\title{
Comparing MADM and artificial neural network methods for evaluating suppliers in multiple sourcing decision
}

\author{
Moloud Sadat Asgari ${ }^{\mathrm{a}}$ and Abbas Abbasi ${ }^{\mathrm{b}^{*}}$
}

${ }^{a}$ Master of Art in industrial Management, Management Department, Shiraz University, Shiraz, Iran

${ }^{b}$ Assistance Professor, Management Department, Shiraz University, Shiraz, Iran

\begin{tabular}{l}
\hline C H R O N I C L E \\
\hline Article history: \\
Received July 10, 2014 \\
Accepted December 17, 2014 \\
Available online \\
December 18 2014 \\
\hline Keywords: \\
Supplier evaluation \\
MADM methods \\
Artificial Neural Network (ANN) \\
Multiple sourcing
\end{tabular}

\section{A B S T R A C T}

This research seeks to examine and introduce an appropriate method for evaluating and selecting suppliers in multiple sourcing and compares two efficient and effective methods, i.e. MADM and ANN for selecting the suppliers. The results of using the methods are compared with each other by using the measurement criteria such as RMSE, NRMSE, and $\mathrm{R}^{2}$ and they indicate that ANN could perform relatively better than MADM methods.

(C) 2015 Growing Science Ltd. All rights reserved.

\section{Introduction}

In recent decades, due to the rapid growth of environmental variables and the increase of competition, supply chain management has become highly important and companies have to make a strong and consistent relationship with their suppliers in order to be successful in this chain (Senvar et al., 2014) because selecting appropriate suppliers has an important role in reducing the total costs of production systems (Tahriri et al., 2014) and can also have a direct effect on the quality, flexibility, and timely delivery of goods and services to the market (Luo et al., 2009). With globalization of trade and increase of international relations and the possibility of selecting suppliers from all over the world, the complexity of selecting and allocating orders to suppliers has increased (Hadian, 2009). Other issues such as transportation routes, state regulations, political concerns such as sanctions and the increase of exchange rate and the rapid changes in customer preferences have doubled the complexity of the problem and have increased the organization concerns every day for selecting the suppliers. Basically, the problems related to supplier selection are of two types: 1) single sourcing, 2) multiple sourcing. In the first case, the supplier can meet all customer needs while in the second case; none of the suppliers is able to do it alone and the company has to select more than one supplier (Deshmukh \& Vasudevan,

* Corresponding author. Tel:+989177230530

E-mail address: aabbasi@shirazu.ac.ir (A. Abbasi)

(C) 2015 Growing Science Ltd. All rights reserved. doi: $10.5267 /$ j.dsl.2014.12.003 
2014). Supplier selection is a multicriteria problem including both quantitative and qualitative criteria as well as tangible and intangible ones and some of them are contrary to each other; for selecting the right suppliers it is necessary to use an appropriate method. Therefore, and with respect to the fact that few studies have been done on multiple sourcing (Rabie et al., 2011), this research seeks to introduce an appropriate method for optimal supplier selection by comparing MADM and ANN in multiple sourcing.

\section{Literature Review}

As defined by ISO 9000, any organization or individual that provides a product is called a supplier (Arabzadeh, 2011). In general, the supplier selection issue consists of two steps. The first step is to determine the criteria, which are used for selecting the supplier and the second step is to determine an appropriate method for selecting the supplier (Asghari \& Abrishami, 2014).

Most of the articles on supply chain management since 1990 have investigated the relationship between buyer and seller and the supplier selection criteria. Dickson (1996) is one of the first people who investigated the matter. He identified 23 evaluation criteria. Then, Lin and Chen (2004) made a comprehensive review of the articles and specified 183 supplier evaluation criteria for general industries. Watt et al. (2009) introduced 901 supplier evaluation criteria. After a comprehensive review of supplier selection criteria, Setak et al. (2012) identified the criteria of price, quality, and delivery time as the most important and the most practical evaluation criteria. These criteria have been expressed generally and regardless of the type of industry and company while the supplier selection criteria of each organization are determined by the organization experts and decision-makers depending on the type of industry and the specific circumstances of each organization.

A lot of methods have been used for selecting the supplier and the first written evidence traces back to 1968 including multiple attribute decision making (MADM), mathematical programming, artificial intelligence, fuzzy set theory, and combinations of these methods. Some of the methods are briefly discussed in the following.

Shannon Entropy: when the data of a decision making matrix are fully specified, the entropy method can be used to evaluate the weights. In information theory, entropy is a measure of uncertainty which is expressed by the identified probability distribution $p_{i}$ (Azar \& Rajabzadeh, 2011).

Analytic Hierarchy Process (AHP) (Saaty, 1988, 1990): in this method, the components on each level of the hierarchy are compared in pairs and their relative preferences to each other are specified. This method is not applicable when there are a large number of options or criteria or when they are correlated (Sepahvaand, 2014).

Simple Additive Weighting Method (SAW): is a simple method which is capable of ranking the options. In this method, the data should be normalized linearly and there should be no correlation between the criteria. Otherwise, it might lead to wrong results (Azar \& Rajabzadeh, 2011).

Technique for Order Preference by Similarity (TOPSIS) (Hwang \& Yoon, 1981): this technique is based on the concept that the selected option should have the minimum distance to the positive ideal solution $\left(\mathrm{A}_{i}^{+}\right)$and the maximum distance to the negative ideal distance $\left(\mathrm{A}_{i}{ }^{-}\right)$. It should be noted that in this method the data should be normalized via Euclidean norm (Feizi \& Solookdar, 2014).

Artificial Neural Network (ANN): by processing the existing data, ANN transfers the knowledge or the principles behind the data into the network structure and learns the general rules based on calculations on numerical data or examples (Kabir \& Sumi, 2013).

Each supplier selection method has its own advantages and disadvantages. MADM methods are very simple and applicable ones, but they strongly depend on subjective judgments of the decision makers (Khalili et al., 2013) because these methods require the criteria weight for evaluation; any mistake in 
determining the weights will lead to unreliable results. Moreover, the credibility of the majority of MADM methods is questioned when there is interdependence between the criteria. Another disadvantage of these methods is the high volume of calculations for finding paired comparisons and lack of their application in uncertainty and imprecise conditions. Furthermore, it is very difficult to use them when there is a large number of criteria or options (Amiri and Jahani, 2010; Karbasian et al., 2011; Ozkan \& Inal, 2014; Mohaghari et al., 2014). Mathematical programming is also confronting a big problem for considering the qualitative criteria. These methods need arbitrary ideal levels and can't match with the subjective characteristics of the decision makers. They also contain complexity and difficult mathematical computations (Pal et al., 2013).

ANN method, which is a subset of artificial intelligence methods, is a new method for evaluating and selecting suppliers. Since these methods automatically learn from historical data, they do not have to determine the weight of criteria. Thus, they do not depend on subjective judgments, learn the linear relationship between dependent and independent variables very easily, are very accurate and fast, and have better performance than the traditional methods particularly when there are a lot of criteria or options and also in uncertainty and complex conditions (Boer, 2001; Luo et al., 2009; Kuo et al., 2010; Vahdani et al., 2012; Alexander et al., 2014). One of the disadvantages of these methods is that they need large amounts of data for network training, and for newly established companies or the companies that have not been previously cooperating with the suppliers the data should be created according to the experts' ideas which will be followed by the risk of subjective judgment.

Many studies conducted in the field of supplier selection have made use of MADM methods and particularly AHP. In a few cases, TOPSIS, SAW, and ANN methods have been used some of which will be mentioned. Choy et al. (2003) used ANN method to benchmark the potential suppliers in an airconditioning manufacturing company and then used case based reasoning (CBR) technique to select the best suppliers. Franklin et al. (2005) offered a new method called voting analytic hierarchy process (VHP) to select the furniture industry suppliers. In this method, a new weighting is used instead of AHP pairwise comparison for supplier selection. Ha and Krishnan (2008) selected the suppliers of a car spare part manufacturing factory. They first used AHP method to evaluate the suppliers' performance with regard to qualitative criteria. Then, they transferred the remaining quantitative criteria along with each supplier scores which were calculated by AHP to DEA and ANN in order to measure the efficiency of each supplier performance.

$\mathrm{Wu}(2009)$ made use of two modules with numerical examples to select suppliers. In the first module, he divided the suppliers into two efficient and inefficient groups based on the obtained efficiency scores and by using DEA. In the second module, he used the data associated with the supplier performance in ANN model and decision tree. Luo et al. (2009) selected some potential suppliers among a lot of suppliers in electrical machinery and equipment manufacturing industry in China by making use of ANN at early stages of supplier selection. They ultimately stated the method was very applicable when there were a lot of suppliers. Karimi and Salmasi (2010) selected evaluation criteria in ISOICO Company using ANN and then they used data mining to determine the credit level of the suppliers. Aksoy and Ozturk (2011) used ANN to evaluate the suppliers of JIT system in a car manufacturing company.

Zeydan et al. (2011) used a combined approach to select suppliers for a car manufacturing company. First, they used fuzzy AHP to determine the weight of criteria and then they used fuzzy TOPSIS method to evaluate the suppliers. Finally, they converted qualitative criteria to quantitative ones and entered the data into DEA. Karbasian et al. (2011) used fuzzy AHP to determine the weight of suppliers' agility measurement criteria and then used fuzzy TOPSIS to rank six suppliers and at the same time used interpretive structural model to interpret the effect of criteria on the agility of the suppliers. Arabzade (2011) used ANN for classification of purchase items and primary supplier evaluation with numerical examples and then used the Shannon entropy to rank the suppliers based on the purchase items. Mokhtari et al. (2013) used fuzzy AHP to determine the weight of criteria and then used fuzzy VIKOR 
method to evaluate the suppliers of a textile factory. Lakshmanpriya et al. (2013) first determined the weight of criteria and suppliers using AHP and then selected the best suppliers in a transformer manufacturing company using ANN algorithm. Seydi and Mozafari (2014) used fuzzy TOPSIS method for supplier evaluation with numerical example and then applied mixed integer linear programming to allocate orders to the suppliers. Rouyendegh and Saputro (2014) selected the suppliers by numerical examples in two stages. In the first stage, they found the best suppliers by using fuzzy TOPSIS model and in the second stage they combined both qualitative and quantitative criteria of supplier evaluation by using Multi- Choice Goal Programming.

\section{Research Method}

This is an applied research in nature (objective or orientation) because general models have been used for selecting the suppliers. The research population includes suppliers of raw milk Zarrin Ghazal Company (producing ice cream and dairy).Manufacturing systems of dairy factories are very similar to

JIT systems because of early spoilage of raw materials, so that the raw materials are supplied for the factory on a daily basis and the products are distributed to the market immediately after production. This has led to the removal of warehouses. Therefore, evaluating and selecting suppliers in such companies are more important than any other companies. Since none of the suppliers is able to supply the required capacity of the company by itself the problem is multiple sourcing; and since the research aims to compare MADM and ANN methods for supplier evaluation, MADM methods are needed to rank the suppliers.

SAW and TOPSIS methods are appropriate for this purpose, and since these methods require the weight of criteria for calculation and the weights greatly affect the results, the Shannon entropy and AHP are used to determine the weight of criteria and then the results will be compared. Supplier evaluation criteria include quality, delivery time, production capacity, price, geographical location, commitment, and transportation service (Abbasi \& Asgari, 2014). Since there should not be any correlation between the criteria, price which is directly correlated with quality (the better the quality, the higher the price) will be removed from the criteria. In ANN method, there is no need to determine the weight of criteria and their correlation is not important, either; however, as we intent to compare the results of three methods the abovementioned criterion is also eliminated in this method. Finally, the results will be compared using the measurement tools such as RMSE, NRMSE, and $\mathrm{R}^{2}$. The tool used in this research to collect data is the interview and data analysis tools are MATLAB, TOPSIS solver, Expert choice, and Excel software.

\section{Data Implementation}

\subsection{Data Implementation Using ANN Model}

In this study, the most famous ANN model, that is, multilayer perceptron (MLP) has been used. Perecptron network includes an input layer, an output layer, and one or several hidden layers. The number of hidden layers and the type of functions are determined by the researcher and by testing the number of different layers and functions. Each function and number of layers which have lower RMSE and higher $\mathrm{R}^{2}$ are more desirable. In this research, more than 500 experiments have been carried out to achieve an optimal network. In order to reduce the size of tables, the most desirable results are displayed in Table (1). According to the results of RMSE and $\mathrm{R}^{2}$ which are displayed in Table 1, the network with two hidden layers and sigmoid logarithmic functions is the best option that is selected. Moreover, input layers contain 6 neurons (supplier selection criteria), hidden layers contain 5 and 10 neurons, respectively and output layer contains one neuron (each supplier point). In order to achieve better responses, the input data of network have been normalized linearly. The network has been trained by 100 data, and the network itself selects $70 \%$ of the data as training data, the next $15 \%$ as checking data, and the last $15 \%$ as testing data. Using training data, the network learns and finds the hidden pattern between the layers. Checking data are used to prevent over-fitting, and testing data are used for 
prediction (15 sample suppliers in this research entered the network as testing data). MATLAB R2014a software is used to run ANN.

$$
\log \operatorname{sig}(n)=\frac{1}{(1+\exp (-n))}
$$

Table 1

The results of the number of neurons and the type of functions

\begin{tabular}{|c|c|c|c|c|c|}
\hline \multicolumn{2}{|c|}{ Number of hidden layer } & \multicolumn{2}{|c|}{ Activation function } & RMSE & $\mathrm{R}^{2}$ \\
\hline \multirow{3}{*}{ One layer } & Linear & & & 2.104 & 0.295 \\
\hline & \multicolumn{3}{|l|}{ tangent sigmoid } & 0.093 & 0.893 \\
\hline & \multicolumn{3}{|l|}{ Log-sigmoid } & 0.080 & 0.955 \\
\hline \multirow{6}{*}{ Two layer } & tangent sigmoid & \multicolumn{2}{|c|}{ Linear } & 0.060 & 0.887 \\
\hline & tangent sigmoid & \multicolumn{2}{|c|}{ Log-sigmoid } & 0.040 & 0.926 \\
\hline & tangent sigmoid & \multicolumn{2}{|c|}{ tangent sigmoid } & 0.096 & 0.902 \\
\hline & Log-sigmoid & \multicolumn{2}{|c|}{ Linear } & 0.202 & 0.939 \\
\hline & Linear & \multicolumn{2}{|c|}{ Linear } & 0.270 & 0.678 \\
\hline & Log-sigmoid & \multicolumn{2}{|c|}{ Log-sigmoid } & 0.022 & 0.939 \\
\hline \multirow{8}{*}{ Three layer } & tangent sigmoid & tangent sigmoid & Linear & 0.045 & 0.756 \\
\hline & tangent sigmoid & Linear & Linear & 0.093 & 0.577 \\
\hline & tangent sigmoid & tangent sigmoid & Log-sigmoid & 0.082 & 0.821 \\
\hline & tangent sigmoid & tangent sigmoid & tangent sigmoid & 0.048 & 0.844 \\
\hline & Log-sigmoid & Log-sigmoid & Linear & 0.147 & 0.952 \\
\hline & Log-sigmoid & Linear & Linear & 0.234 & 0.968 \\
\hline & Log-sigmoid & Log-sigmoid & Log-sigmoid & 0.036 & 0.398 \\
\hline & Linear & Linear & Linear & 0.221 & 0.889 \\
\hline
\end{tabular}

\subsection{Data Implementation Using MADM Methods}

In this section the sample data are run using SAW and TOPSIS methods. As mentioned before, the data should be normalized as linear norm for SAW and Euclidean norm for TOPSIS. Moreover, the weights of criteria should be determined, as well. The weights have been determined once through the Shannon entropy and another time through AHP (Table 2 illustrates the determined weight of criteria by both methods). It should be noted that Excel software is used for SAW and Shannon entropy, TOPSIS Solver 2012 v3.2 software is used for TOPSIS method and Expert Choice 11 software is used for AHP method and the inconsistency rate of AHP pairwise comparison is 0.04 which is smaller than 0.1 , indicating the acceptable precision of the pairwise comparison. In Table 2, the weights of 1, 2, 3, 4, 5, and 6 are respectively related to quality, delivery time, production capacity, geographical location, commitment, and transportation service.

Table 2

The Weights of criteria using Shannon entropy and AHP methods

\begin{tabular}{rcccccc}
\hline & $\mathrm{W}_{1}$ & $\mathrm{~W}_{2}$ & $\mathrm{~W}_{3}$ & $\mathrm{~W}_{4}$ & $\mathrm{~W}_{5}$ & $\mathrm{~W}_{6}$ \\
\hline Shannon Entropy & 0.0328 & 0.0065 & 0.3160 & 0.5970 & 0.0157 & 0.0320 \\
AHP & 0.317 & 0.133 & 0.070 & 0.030 & 0.133 & 0.317 \\
\hline
\end{tabular}

\section{Results and Discussion}

In this section, supplier evaluation in each criterion and the output of three methods are explained as shown in Table 3. Quality represents the average microbial load per one milliliter of milk which is calculated whenever the milk enters the company (this criterion has a negative nature, i.e. the lower the better). Delivery time and commitment are evaluated by the experts according to the Likert 5-point scale as excellent (5), good (4), average (3), poor (2) and unacceptable (1) (positive). Production 
capacity indicates the tons of milk the supplier is able to produce per day (positive). Geographical location is calculated based on the distance of supplier from the company (negative). Transportation service indicates that whether the supplier has a tanker to transport milk to the company or not; Yes (1), No (0) (positive).

Table 3

Suppliers evaluation criteria and their output in each method

\begin{tabular}{lccccccccccc}
\hline \multirow{2}{*}{ Supplier } & \multirow{2}{*}{$\mathrm{C}_{1}$} & \multirow{2}{*}{$\mathrm{C}_{2}$} & \multirow{2}{*}{$\mathrm{C}_{3}$} & \multirow{2}{*}{$\mathrm{C}_{4}$} & $\mathrm{C}_{5}$ & \multirow{2}{*}{$\mathrm{C}_{6}$} & \multirow{2}{*}{ ANN } & \multicolumn{2}{c}{ Shannon Entropy } & \multicolumn{2}{c}{ AHP } \\
& 950 & 3 & 0.08 & 0.8 & 3 & 0 & 0.040 & 0.145 & 0.1885 & 0.229 & 0.0942 \\
$\mathrm{~S}_{1}$ & 550 & 4 & 0.1 & 0.2 & 3 & 1 & 0.193 & 0.432 & 0.5716 & 0.615 & 0.6371 \\
$\mathrm{~S}_{2}$ & 500 & 4 & 0.08 & 1 & 3 & 1 & 0.262 & 0.167 & 0.0519 & 0.593 & 0.6565 \\
$\mathrm{~S}_{3}$ & 950 & 3 & 0.12 & 1 & 3 & 0 & 0.046 & 0.153 & 0.0269 & 0.230 & 0.0937 \\
$\mathrm{~S}_{4}$ & 850 & 3 & 0.3 & 1 & 3 & 0 & 0.072 & 0.260 & 0.1367 & 0.245 & 0.1271 \\
$\mathrm{~S}_{5}$ & 450 & 4 & 0.1 & 0.4 & 3 & 1 & 0.235 & 0.274 & 0.4877 & 0.606 & 0.6838 \\
$\mathrm{~S}_{6}$ & 50 & 2 & 0.1 & 0.8 & 4 & 1 & 0.596 & 0.217 & 0.2004 & 0.848 & 0.8035 \\
$\mathrm{~S}_{7}$ & 50 & 4 & 1 & 0.3 & 4 & 1 & 0.942 & 0.894 & 0.9033 & 0.990 & 0.9930 \\
$\mathrm{~S}_{8}$ & 700 & 4 & 1 & 0.9 & 3 & 1 & 0.466 & 0.723 & 0.4709 & 0.649 & 0.5950 \\
$\mathrm{~S}_{9}$ & 900 & 3 & 0.2 & 1 & 3 & 1 & 0.110 & 0.234 & 0.0888 & 0.554 & 0.5001 \\
$\mathrm{~S}_{10}$ & 950 & 2 & 1 & 1 & 3 & 1 & 0.390 & 0.707 & 0.4344 & 0.576 & 0.4976 \\
$\mathrm{~S}_{11}$ & 950 & 2 & 0.8 & 0.8 & 2 & 0 & 0.046 & 0.569 & 0.4568 & 0.213 & 0.1318 \\
$\mathrm{~S}_{12}$ & 650 & 4 & 0.2 & 0.2 & 3 & 1 & 0.199 & 0.491 & 0.6010 & 0.618 & 0.5970 \\
$\mathrm{~S}_{13}$ & 950 & 3 & 0.75 & 0.3 & 3 & 0 & 0.118 & 0.676 & 0.8006 & 0.288 & 0.1557 \\
$\mathrm{~S}_{14}$ & 50 & 2 & 0.85 & 0.2 & 4 & 1 & 0.685 & 0.902 & 0.9049 & 0.923 & 0.8715 \\
$\mathrm{~S}_{15}$ & & & & & & & & & & &
\end{tabular}

To assess the utility of the methods and to compare them with each other RMSE, NRMSE, and $\mathrm{R}^{2}$ methods have been used. The results are summarized in Table (4). (The table associated with RMSE is organized from small to large). The values are numbers between 0 and 1 due to the normalized data. As the RMSE and NRMSE get closer to 0 and $\mathrm{R}^{2}$ gets closer to 1 , the method is more efficient.

Table 4

Network measurement parameters

\begin{tabular}{lrrrr}
\hline Method for determining weights of criteria & Method & RMSE & NRMSE & $\mathrm{R}^{2}$ \\
\hline- & ANN & 0.0795 & 0.2125 & 0.9141 \\
AHP & TOPSIS & 0.2636 & 0.7047 & 0.7669 \\
AHP & SAW & 0.2920 & 0.7804 & 0.830 \\
Shannon Entropy & TOPSIS & 0.3076 & 0.8222 & 0.2672 \\
Shannon Entropy & SAW & 0.3176 & 0.8490 & 0.2493 \\
\hline
\end{tabular}

$$
\begin{aligned}
& R M S E=\sqrt{\frac{\sum_{i=1}^{n}\left(p_{i}-\hat{p}_{i}\right)^{2}}{N}}, \\
& N R M S E=\sqrt{\frac{\sum_{i=1}^{n}\left(p_{i}-\hat{p}_{i}\right)^{2}}{\sum_{i=1}^{n} p_{i}^{2}}}, \\
& R^{2}=\frac{\sum_{i=1}^{n}\left(p_{i}-\bar{p}_{i}\right)\left(\hat{p}_{i-} \bar{p}_{i}\right)}{\sqrt{\sum_{i=1}^{n}\left(p_{i}-\bar{p}_{i}\right)^{2} \sum_{i=1}^{n}\left(\hat{p}_{i-} \overline{\hat{p}}_{i}\right)^{2}}} .
\end{aligned}
$$

Where $p i$ is the real output, $p \hat{i} i$ is the output predicted by the network, $n$ is the number of the data, $\overline{p i}$ is the mean of real outputs and $\overline{p i}$ is the mean for the predicted outputs 
Comparison of the results shows that ANN performance is significantly better than the other two methods, so that it got a much lower score in RMSE and NRMSE criteria and a much greater score in

$\mathrm{R}^{2}$. The performance of SAW and TOPSIS when the criteria are determined by AHP method is very different from the time when their performance is determined by Shannon entropy which indicates the significant effect of the weight of criteria on performance in MADM methods. Nevertheless, determining the weight of criteria by AHP method has led to better results and lower errors. Moreover, the comparison of the results of TOPSIS and SAW methods in both weighting methods show that TOPSIS performance is relatively better than SAW performance.

\section{Conclusion and Suggestions}

Producers with JIT production systems require long-term relationships with reliable suppliers because the reliable suppliers enable the producers to reduce the cost of inventory and to improve the quality of products. Therefore, selecting appropriate suppliers for producers is highly important (Aksoy \& ozturk, 2011) and they should be selected via a proper method. Hence, this study has sought to investigate and introduce an appropriate method for this critical decision. Therefore, it has compared two appropriate methods of supplier selection, i.e. MADM and ANN methods in Zarrin Ghazal Company (whose production system is like JIT system). Since none of the suppliers is able to supply the required capacity of the company by itself the problem is multiple sourcing. In order to use MADM methods, the criteria must be independent of each other and their weight should be determined, as well. Therefore, price is eliminated due to its correlation with quality and in order to assess the effect of the weights of criteria on the methods, the weights have been determined through AHP and Shannon entropy methods.

The accuracy of different methods has been assessed using the measurement standards of RMSE, NRMSE, and $\mathrm{R}^{2}$. The results indicate much better performance of ANN than MADM methods. Furthermore, the results indicate high dependency of MADM methods on the weights of criteria, so that the results with similar methods and data were significantly different for different weights. Nevertheless, determining the weight of criteria by AHP method has led to better results and lower errors. Moreover, in both weighting methods TOPSIS performance is relatively better than SAW performance. As ANN learns the rules that lie beyond the data from historical data, it does not need the weights of criteria and so its prediction and evaluation is much more accurate. Moreover, this method deals with the criteria dependency very easily.

The results of the other studies that have previously used ANN method are as the following. Choy et al. (2003) showed that ANN significantly reduces the outsourcing cycle time (since seeking the potential supplier until allocating orders). Ha and Krishnan (2008) have concluded that ANN considers both quantitative and qualitative criteria and is also appropriate for supplier selection in single sourcing and multiple sourcing. $\mathrm{Wu}$ (2009) concluded that ANN can deal with complexity and uncertainty and also tangible and intangible criteria quite well. Luo et al. (2009) concluded that this method works very well when there are a lot of suppliers, and it considers both quantitative and qualitative criteria, is able to learn, is easier than fuzzy methods, can classify the suppliers quickly and automatically, and the company decision makers don't need to know the details to work with ANN and should just enter the data to the network. The network automatically produced the outputs. Aksoy and Ozturk (2011) have figured out that this method is very efficient and effective in JIT production conditions. The results of the research are consistent with previous findings.

The following points can be offered as suggestions.

1. The companies that are planning to use ANN for supplier selection are suggested to keep all their experiences in this field in the firm as documentation because ANN requires historical data for training. Moreover, more accurate evaluation of suppliers will lead to the increase of network accuracy and better results. 
2. Zarrin Ghazal Company is suggested to encourage its suppliers to promote capacity, quality, and commitment by applying some methods such as sharing the profits with them because JIT systems require long term relationships with a few suppliers.

3. In future studies, it is possible to investigate the performance of implemented model in fuzzy space and compare the results with the finding of the present research.

\section{References}

Abbasi, A. \& Asgari, M.S. (2014). Supplier selection using adaptive neuro-fuzzy inference system and Fuzzy Delphi. International Journal of Operations and Logistics Management, 3 (4), 351-371.

Aksoy, A. \& Ozturk, N. (2011). Supplier selection and performance evaluation in just-in-time production environments. Expert systems with applications, 38 (5), 6351-6359.

Alexander, A., Walker, H. \& Naim, M. (2014). Decision theory in sustainable supply chain management: a literature review. Supply Chain Management: An International Journal, 19 (5/6), $504-522$

Amiri, M. \& Jahani, S. (2010). Applying AHP IDEA method for evaluating and selecting suppliers. Journal of Industrial Management, 2 (5), 5-18.

Arabzadeh, S.M. (2011). Designing a neural network approach for suppliers and allocating purchase orders based on Kraljic Model, Master Thesis, Islamic Azad University, Najaf Abad Branch.

Asghari, M. \& Abrishami, S.J. (2014). Weighting Suppliers Using Fuzzy Inference System and Gradual Covering in a Supply Chain Network. Proceedings of the 2014 International Conference on Industrial Engineering and Operations Management Bali, Indonesia, January 7 - 9, 2014.

Azar, A. \& Rajabzadeh, A. (2011). Practical decision making via MADM approach, Tehran, Negah-e Danesh, $1^{\text {st }}$ Edition.

Boer, L.D., Labro, E. \& Morlacchi, P. (2001). A review of methods supporting supplier selection. European Journal of Purchasing \& Supply Management, 7 (2), 75-89.

Choy, K.L., Lee, W.B. \& Lo, V. (2003). Design of an intelligent supplier relationship management system: a hybrid case based neural network approach. Expert Systems with Applications, 24 (2), 225 237.

Deshmukh, A.J. \& Vasudevan, H. (2014). Emerging supplier selection criteria in the context of traditional vs green supply chain management. International Journal of Managing Value and Supply Chains, 5 (1), 19-33.

Dickson, G.W. (1996). An analysis of vendor selection systems and decisions. Journal of Purchasing, 2 (1), 28-41.

Feizi, A. \& Solookdar, A. (2014). Evaluating banking industry performance with integrated approach of fuzzy TOPSIS- Balanced Scorecard (FTOPSIS-BSC). Journal of Financial Engineering and Exchange Management, 20, 57-78.

Franklin, L., Hai, F-H \& Lin, H. (2005). The voting analytic hierarchy process method for selecting supplier. Journal of Production Economics, 97, 308-317.

Ha, S.H. \& Krishnan, R. (2008). A hybrid approach to supplier selection for the maintenance of a competitive supply chain. Expert Systems with Applications, 34 (2), 1303-1311.

Hadian, Hengameh. (2009). Suppliers selection and allocation of orders in discount conditions in a supply chain system using Multiple Attribute Decision Making methods, Master thesis, Sharif University of Technology.

Hwang, C. L., \& Yoon, K. (1981). Multiple attributes decision making methods and applications. New York: Springer.

Kabir, G. \& Sumi, R.S. (2013). Integrating fuzzy Delphi with fuzzy analytic hierarchy process for multiple criteria inventory classification. Journal of engineering, project, and production management, 3 (1), 22-34. 
Karbasian, M. Khaboshani, A., Javanmardi, M., Zanjrichi, S.M. (2011). Application of ISM for classifying agile supplier selection indices and ranking them using fuzzy TOPSIS-AHP model. Journal of Production and Operations Management, 2 (2), 22-107.

Karimi, H. \& Salmasi, N. (2010). Application of neural networks in selecting evaluation criteria and the use of data mining in determining the characteristics of suppliers credit levels (Case Study: ISOICO Company). Industrial Engineering and Management, Sharif University, Course 1-28, 1, 113-120.

Khalili-Damghani, K., Dideh-Khani, H., \& Sadi-Nezhad, S. (2013). A two-stage approach based on ANFIS and fuzzy goal programming for supplier selection. Int. J. Applied Decision Sciences, 6 (1), $1-14$.

Kuo, R.J., Hong, S.Y. \& Huang, Y.C. (2010). Integration of particle swarm optimization-based fuzzy neural network and artificial neural network for supplier selection. Applied Mathematical Modelling, 34 (12), 3976-3990.

Lakshmanpriya, C., Sangeetha, N. \& Lavanpriya, C. (2013). Vendor selection in manufacturing industry using AHP and ANN. The SIJ Transactions on Industrial, Financial \& Business Management, 1 (1), 29-34.

Lin, C.W. \& Chen, H.Y. (2004). A fuzzy strategic alliance selection framework for supply chain partnering under limited evaluation resources. Computers in industry, 55 (2), 159-179.

Luo, X., Wu, C.h., Rosenberg, D. \& Barnes, D. (2009). Supplier selection in agile supply chains: An information-processing model and an illustration. Journal of Purchasing \& Supply Management, 15 (4), 249-262.

Mohaghari, A. Kashef, M. \& Khanmohammadi, E. (2014). A Novel Technique to Solve the Supplier Selection Problems: Combination of Decision Making Trial \& Evaluation Laboratory, Graph Theory and Matrix Approach Methods. International Journal of Industrial Engineering \& Production Research, 25 (2), 103-113.

Mokhtari, M., Javanshir, H., Dolatabadi, M.K., Tashakori, L. \& Madanchi, F. (2013). Supplier selection in textile industry using MADM. Research journal of applied science, engineering and technology, $6(3), 400-411$.

Ozkan, G. \& Inal, M. (2014). Comparison of neural network application for fuzzy and ANFIS approaches for multi-criteria decision making problems. Applied Soft Computing, DOI: http://dx.doi.org/doi:10.1016/j.asoc.2014.06.032

Pal, O., Gupta, A.K. \& Garg, R.K. (2013). Supplier Selection Criteria and Methods in Supply Chains: A Review. International Journal of Social, Management, Economics and Business Engineering, 7 (10), 1403-1409.

Rabie, M., Azar, A., Modares Yazdi, M. \& Fetanat Fard Haghighi, M. (2011). Planning mathematical model of multipurpose stable sourcing: An Approach to Reduce Supply Chain Risk (Case Study: Iran Khodro Supply Chain), Industrial Management Perspective, 1, 57-77.

Rouyendegh, B.D. \& Saputro, T.E. (2014). Supplier selection using integrated fuzzy TOPSIS and MCGP: a case study. Procedia - Social and Behavioral Sciences, 116, 3957- 3970.

Saaty, T. L. (1988). What is the analytic hierarchy process? (pp. 109-121). Springer Berlin Heidelberg.

Saaty, T. L. (1990). How to make a decision: the analytic hierarchy process. European journal of operational research, 48 (1), 9-26.

Senvar, O., Tuzkaya, G. \& Kahraman, C. (2014). Multi criteria supplier selection using fuzzy PROMETHEE method. Studies in fuzziness and soft computing, 313, 21-34.

Sepahvaand, R. (2014). Application of QFD and AHP approaches in supplier selection with a case study of Zamzam Company, Journal of Operations Research and Its Applications, 11(1), 19-30.

Setak, M., Sharifi, S. \& Alimohammadian, A. (2012). Supplier selection and order allocation models in supply chain management: a review. World applied sciences journal, 18 (1), 55-72.

Seydi, M. \& Mozafari, M. (2014). Planning a model for selecting suppliers using a combination of hierarchical fuzzy TOPSIS technique and linear programming. The First National Conference on Industrial Engineering Research, Hamadan, Tolooe Farzin Science and Industry Company, http://www.civilica.com/Paper-RIEEM01-RIEEM01_036.html 
Tahriri, F., Mousavi, M., Haghighi, S.H. \& Dawal, S.Z.M. (2014). The application of fuzzy Delphi and fuzzy inference system in supplier ranking and selection. Journal of Industrial Engineering International, DOI 10.1007/s40092-014-0066-6

Vahdani, B., Iranmanesh, S.H., Mousavi, S.M. \& Abdollahzade, M. (2012). A locally linear neurofuzzy model for supplier selection in cosmetics industry. Applied Mathematical Modelling, 36 (10), 4714-4727.

Watt, D. J., Kayis, B., \& Willey, K. (2009). Identifying key factors in the evaluation of tenders for projects and services. International Journal of Project Management, 27(3), 250-260.

Wu, D. (2009). Supplier selection: A hybrid model using DEA, decision tree and neural network. Expert Systems with Applications, 36 (5), 9105-9112.

Zeydan, M., Colpan, C. \& Cobanoglu, C. (2011). A combined methodology for supplier selection and performance evaluation. Expert Systems with Applications, 38 (3), 2741-2751. 